\title{
Effect of chronic clonidine treatment on transmitter release from sympathetic varicosities of the guinea-pig vas deferens
}

\author{
${ }^{1}$ David Knight, ${ }^{2}$ Tom C. Cunnane \& *,1 Nickolas A. Lavidis \\ ${ }^{1}$ The Narcotics Research Laboratory, School of Biomedical Sciences, Department of Physiology and Pharmacology, The \\ University of Queensland, St. Lucia, Queensland, Australia, 4072 and ${ }^{2}$ The University Department of Pharmacology, \\ Mansfield Road, Oxford, OX1 3QT
}

1 Previous studies have demonstrated that chronic pre-synaptic inhibition of transmitter release by morphine evokes a counter-adaptive response in the sympathetic nerve terminals that manifests itself as an increase in transmitter release during acute withdrawal. In the present study we examined the possibility that other pre-synaptically acting drugs such as clonidine also evoke a counter-adaptive response in the sympathetic nerve terminals.

2 In chronically saline treated (CST) preparations, clonidine $(0.5 \mu \mathrm{M})$ completely abolished evoked transmitter release from sympathetic varicosities bathed in an extracellular calcium concentration $\left(\left[\mathrm{Ca}^{2+}\right]_{\mathrm{o}}\right)$ of $2 \mathrm{mM}$. The inhibitory effect of clonidine was reduced by increasing $\left[\mathrm{Ca}^{2+}\right]_{\mathrm{o}}$ from 2 to $4 \mathrm{~mm}$ and the stimulation frequency from 0.1 to $1 \mathrm{~Hz}$.

3 The nerve terminal impulse (NTI) was not affected by concentrations of clonidine that completely abolished evoked transmitter release.

4 Sympathetic varicosities developed a tolerance to clonidine $(0.5 \mu \mathrm{M})$ following $7-9$ days of chronic exposure to clonidine.

5 Acute withdrawal of preparations following chronic clonidine treatment (CCT) resulted in a significant $(P<0.005)$ enhancement of neurotransmitter release $(3.75$ times $)$ above control levels observed in CST preparations.

6 The present findings demonstrate an enhancement of neurotransmitter release from sympathetic varicosities following acute withdrawal from chronic clonidine treatment.

British Journal of Pharmacology (2001) 134, 1480-1486

Keywords: Acute withdrawal; clonidine; guinea-pig; neurotransmission; sympathetic varicosities; tolerance

Abbreviations: CCT, chronic clonidine treatment; CST, chronic saline treatment; EJC, excitatory junction current; NTI, nerve terminal impulse; SEJC, spontaneous excitatory junction current

\section{Introduction}

Clonidine is an $\alpha_{2}$-adrenoceptor agonist that greatly reduces transmitter release from noradrenergic terminals. This inhibition has been proposed to occur via two mechanisms. One mechanism involves blockade of impulse propagation and the other involves a reduction in the calcium available for evoked release. Activation of $\alpha_{2}$-adrenoceptors located on the cell soma of neurons has been shown to increase the $\mathrm{K}^{+}$ conductance resulting in reduced excitability of the cell membrane (Brown \& Caulfield, 1979; Cole \& ShinnickGallagher, 1981; Andrade \& Aghajanian, 1985; North \& Surprenant, 1985; Williams et al., 1985). The second mechanism involves a reduction in the calcium available for transmitter release. The clonidine-induced inhibition in transmitter release is reduced by procedures that are thought to increase the cytosolic calcium concentration such as: increasing $\left[\mathrm{Ca}^{2+}\right]_{\mathrm{o}}$, increasing the frequency of nerve stimulation, or increasing the duration of the nerve terminal impulse (NTI) with $\mathrm{K}^{+}$channel blockers (Alberts et al., 1981; Ebstein et al., 1982; Schoffelmeer \& Mulder, 1983; Wakade \& Wakade, 1983; Starke, 1987). More direct studies have shown that clonidine reduces calcium currents in sympathetic neurons

*Author for correspondence; E-mail: lavidis@plpk.uq.edu.au
(Horn \& McAfee, 1980; Dunlap \& Fischbach, 1981; Williams \& North, 1985; Boehm \& Huck, 1991). Calcium-imaging studies have demonstrated a decrease in stimulus evoked calcium entry into varicosities following acute clonidine administration (Brain \& Bennett, 1997; O’Connor et al., 1999).

Many researchers believe that the inhibition of calcium is the primary effector in nerve terminals. Some recent work compared the contractions of vasa deferentia from mice without $\alpha_{2 \mathrm{~A}}$-adrenoceptors and mice with a point mutation in the second transmembrane region of the $\alpha_{2 \mathrm{~A}}$-adrenoreceptor that prevents activation of $\mathrm{K}^{+}$currents without affecting the inhibition of $\mathrm{Ca}^{2+}$ current or cyclic AMP production (Surprenant et al., 1992; Altman et al., 1999). Their work showed that mice lacking the receptor displayed very little adrenoceptor mediated modulation of transmitter release, while mice with the mutant adrenoceptors were no different from the control (Altman et al., 1999). This suggests that it is a reduction in the calcium current or cyclic AMP levels that is responsible for the inhibition of transmitter release rather than an activation of potassium conductance. In the present study we have re-examined the effect of clonidine on the NTI along single axons and evoked transmitter release from sympathetic varicosities at frequencies of nerve stimulation in different $\left[\mathrm{Ca}^{2+}\right]_{\mathrm{o}}$. 
Chronic morphine treatment of mice results in the development of tolerance to both morphine (Montel et al., 1975; Einstein \& Lavidis, 1984b; Lavidis, 1995a) and clonidine (Solomon \& Gebhart, 1988; Stevens et al., 1988; Karunanithi \& Lavidis, 2001). Tolerance to both morphine and clonidine in sympathetic nerves develops through a counter-adaptive process, resulting in a substantial increase in the probability of transmitter release from varicosities (Montel et al., 1975; Einstein \& Lavidis, 1984a; Karunanithi \& Lavidis, 2001). In the present study we have investigated whether chronic clonidine treatment (CCT), by acting on different pre-synaptic receptors, evokes similar counteradaptations as seen in chronically morphine treated preparations.

\section{Methods}

\section{Treatment of animals}

Male guinea-pigs aged between 2 and 3 weeks postnatal were chronically treated with either saline (CST) or clonidine (CCT) for 7-9 days. Animals received either saline or clonidine by sub-cutaneous injections $(0.1 \mathrm{ml})$ at $8-\mathrm{h}$ intervals. The dosage of clonidine administered to animals was gradually increased according to the following protocol: days 1 to 2 , animals received $1 \mathrm{mg} \mathrm{kg}^{-1}$; days 3 to 4 , $2 \mathrm{mg} \mathrm{kg}^{-1}$; days 5 to $9 ; 5 \mathrm{mg} \mathrm{kg}^{-1}$. The volume of solution injected sub-cutaneously was kept constant at $0.1 \mathrm{ml}$ as the dosage was increased. On day 8 or 9 , animals were injected with a dose of saline (control) or clonidine and then $2 \mathrm{~h}$ later killed by cervical fracture. Animal housing and treatment conditions complied with the University of Sydney animal ethics approval.

\section{Preparation of tissues}

Both vasa deferentia were dissected from the animal and pinned to the bottom of a $3 \mathrm{ml}$ capacity bath on a bed of Sylgard (Dow Corning). Preparations were continuously

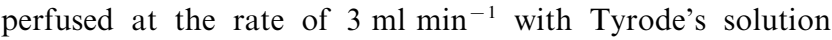
of the following composition (mM): $\mathrm{NaCl}, 123.4 ; \mathrm{KCl}, 4.7$; $\mathrm{MgCl}_{2}, 1.0 ; \mathrm{NaH}_{2} \mathrm{PO}_{4}, 1.3 ; \mathrm{NaHCO}_{3}, 16.3 ; \mathrm{CaCl}_{2}, 1.0-4.0$; glucose, 7.8. Tissue from CCT animals was perfused with Tyrode's solution containing $0.5 \mu \mathrm{M}$ clonidine to prevent withdrawal. The temperature of the bath was maintained between 32 and $34^{\circ} \mathrm{C}$. The reservoir supplying the bath was continuously gassed with $95 \% \mathrm{O}_{2}$ and $5 \% \mathrm{CO}_{2}$, and the $\mathrm{pH}$ was maintained at 7.4 .

\section{Stimulation}

The postganglionic axons near the prostatic end of the vas deferens were gently drawn into a pipette filled with Tyrode's solution. Two silver/silver chloride wires were used to stimulate the sympathetic axons, one inside the pipette and the other on the outside. Square wave pulses of $0.05 \mathrm{~ms}$ duration and $10-17 \mathrm{~V}$ strength were used to stimulate the sympathetic axons. The axons were stimulated continually at $0.1 \mathrm{~Hz}$ while searching for the extracellular signs of the NTI and the excitatory junction current (EJC) (Brock \& Cunnane, 1987; 1988).

\section{Visualization of the sympathetic varicosities}

Preparations were left bathing in Tyrode's solution containing $2 \mathrm{mM}\left[\mathrm{Ca}^{2+}\right]_{\mathrm{o}}$ for about $20 \mathrm{~min}$. They were then bathed for $30 \mathrm{~s}$ in $3-3$ diethyloxardicarbocyanine iodide $\left(\mathrm{DiOC}_{2}(5)\right.$, $0.1 \mu \mathrm{M})$ and then washed with Tyrode's solution for $3 \mathrm{~min}$ (Yoshikami \& Okun, 1984; Lavidis \& Bennett, 1992; 1993a,b). $\mathrm{DiOC}_{2}(5)$-fluorescent terminals were viewed with an image intensifier camera (Panasonic) attached to an Olympus (BH2) microscope equipped with a rhodamine filter set. The image was then displayed on a video monitor (National). The effects of exposing the intervaricose axons and varicosities to $\mathrm{DiOC}_{2}(5)$-fluorescence have been previously examined (Lavidis \& Bennett, 1992). The outline of $\mathrm{DiOC}_{2}(5)$-fluorescent varicosities were traced onto the video monitor screen and the fluorescence was then turned off, avoiding long periods of fluorescence and the necessity for repeated applications of the $\mathrm{DiOC}_{2}(5)$. The preparation was then illuminated using a tungsten filament lamp and any visible structures such as blood vessels, bundles of axons and connective tissues etc. were also traced on the video monitor. The position of the terminal, with respect to such structures, was checked by a short period of refluorescence before searching with an extracellular electrode for signs of the NTI and the EJCs.

\section{Recording}

Extracellular recordings of the NTIs, EJCs and spontaneous EJCs (SEJCs) were obtained using micropipettes $(25 \mu \mathrm{m}$ diameter) filled with the Tyrode's solution. Focal extracellular recordings were obtained by placing the electrode over the visualized varicosities and gently applying suction through the electrode until a slight seal formed between the electrode rim and the smooth muscle cells (Brock \& Cunnane, 1987). The external signs of the NTI and the EJCs could be observed on the oscilloscope after stimulating the hypogastric axons supplying the guinea-pig vas deferens. The position of the electrode rim with respect to the visualized varicosities was adjusted to increase the amplitude of both the NTIs and the EJCs. In some instances, both positive and negative EJCs were recorded reflecting neurotransmitter release outside or inside the recording electrode respectively.

\section{Data analysis}

Analogue recordings of NTIs, EJCs and SEJCs were converted to digital signals using a MacLab system and saved using Scope and Chart software (version 3.3.5) on a Macintosh computer. Amplitude histograms for EJCs and SEJCs were constructed. Estimates of the success rate of recording EJCs were determined by dividing the number of EJCs recorded by the total number of stimulations. The statistically significant differences between two sets of data were determined using Student's $t$-tests. A statistical significance was assumed if $P<0.05$.

\section{Drugs}

Drugs were dissolved in a separate reservoir of about $200 \mathrm{ml}$ capacity. Each reservoir was gassed with $95 \% \mathrm{O}_{2}$ and $5 \%$ $\mathrm{CO}_{2}$. Bathing solutions were changed by means of 3-way 
taps. The intra-electrode solution was changed by a micropump delivering solution at the rate of $0.2 \mathrm{ml} \mathrm{h}^{-1}$. Stock solutions of $\mathrm{DiOC}_{2}(5),(10 \mathrm{mM})$ dissolved in dimethyl sulphoxide (DMSO) were kept refrigerated for up to 6 weeks. This stock solution was serially diluted to $10 \mu \mathrm{M}$ using distilled $\mathrm{H}_{2} \mathrm{O}$ and then to $0.1 \mu \mathrm{M}$ using Tyrode's solution. Clonidine hydrochloride used for electrophysiology experiments was dissolved in distilled $\mathrm{H}_{2} \mathrm{O}$ and kept refrigerated as a stock solution at a concentration of $1 \mathrm{mM}$. Clonidine hydrochloride used for treating the animals was dissolved in saline using aseptic techniques at concentrations of $0.2 \mathrm{mg} \mathrm{ml}^{-1}, 0.4 \mathrm{mg} \mathrm{ml}^{-1}$ and $1 \mathrm{mg} \mathrm{ml}^{-1}$ in vials that were kept at $-20^{\circ} \mathrm{C}$ until needed for injection. Each vial was warmed to $34^{\circ} \mathrm{C}$ before injecting the $0.1 \mathrm{ml}$ of solution into the animal. Idazoxan hydrochloride was dissolved in distilled $\mathrm{H}_{2} \mathrm{O}$ as a stock solution at a concentration of $1 \mathrm{~mm}$.

\section{Results}

\section{Acute effects of clonidine on NTI and neurotransmitter release}

Surface varicosities from the guinea-pig vas deferens were visualized using $\mathrm{DiOC}_{2}(5)$-fluorescence (Figure 1) to aid in positioning extracellular electrodes over groups of 4-6 varicosities. Electrodes with tip diameters of $25 \mu \mathrm{m}$ were placed over single axons to record the NTI and EJCs during stimulation with continuous trains of impulses $(0.1 \mathrm{~Hz})$. Examples of the NTIs and EJCs recorded are shown in Figure 2. Most electrode placements recorded slow (>6 ms rise time), low amplitude $(<40 \mu \mathrm{V}) \mathrm{EJCs}$, even in areas devoid of surface varicosities. Fast ( $\leqslant 6 \mathrm{~ms}$ rise time) EJCs were only recorded if the electrode was placed directly over surface varicosities (verified by $\mathrm{DiOC}_{2}$ (5)-fluorescence). Recording sites were accepted only if the NTI was invariant over a large range of stimulus strengths, thus ensuring that the recording originated from a single axon. Recording sites were then divided into two groups: those that failed to
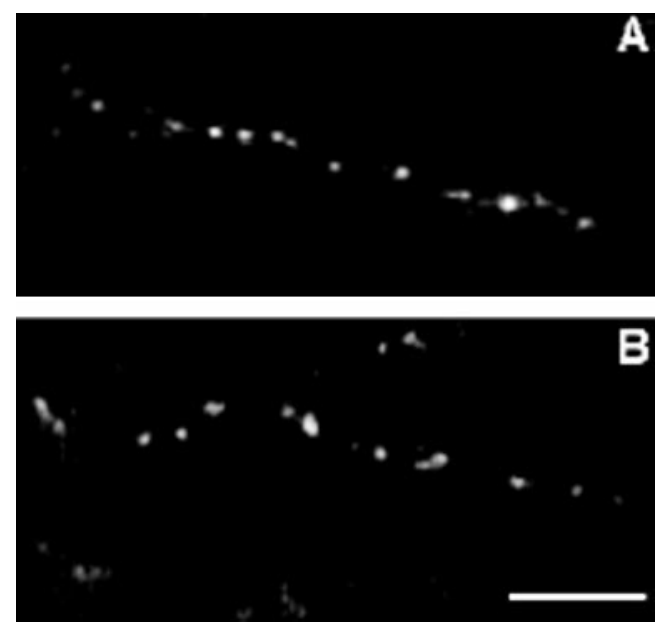

Figure $1 \mathrm{DiOC}_{2}(5)$-fluorescent sympathetic varicosities on the surface of the guinea-pig vas deferens. (A) CST preparation; (B) CCT preparation. Brighter varicosities are closer to the surface while less bright varicosities are below the surface. The calibration bar indicates $20 \mu \mathrm{m}$.

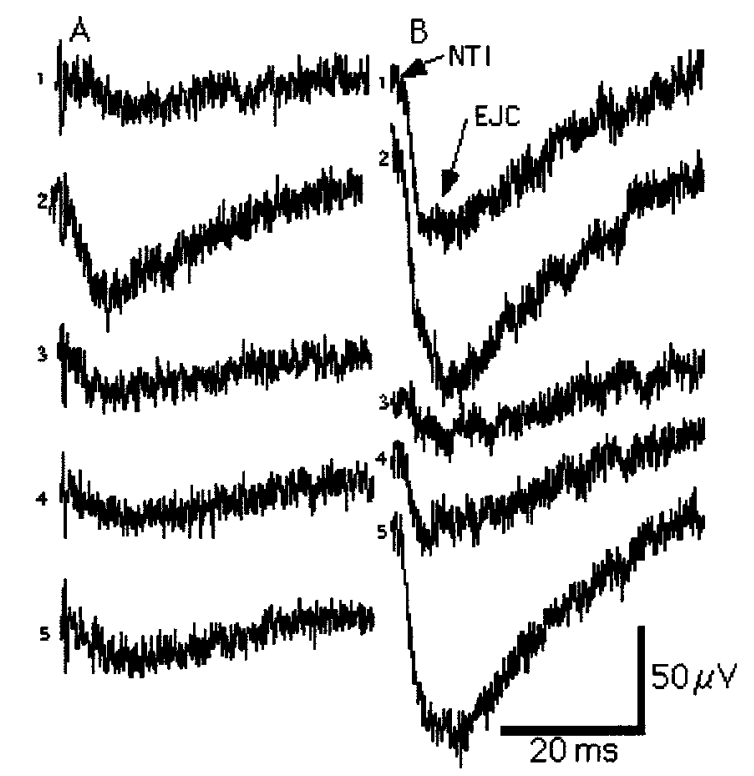

Figure 2 Examples of EJCs recorded from four varicosities along single sympathetic axons. Varicosities were visualized using $\mathrm{DiOC}_{2}(5)$-fluorescence as shown in Figure 1 to aid in placement of the recording electrode. (A) CST preparation with idazoxan $(1 \mu \mathrm{M})$ placed in the bathing solution; (B) CCT preparation bathed in idazoxan $(1 \mu \mathrm{M})$. Five consecutive traces are shown for each group. EJCs with rise times $\leqslant 6 \mathrm{~ms}$ were counted in determining the success rate of recording sites. Slower EJCs were assumed to be emanating from deeply located varicosities (unpublished observation) and thus were not used for estimating the success rate of a set of varicosities.

generate at least one EJC during the first 20 consecutive stimuli, despite the presence of a NTI (i.e. sites with a probability of release less than 0.05 ), and those that generated one or more EJCs during the first 20 consecutive stimuli (release probability $\geqslant 0.05$ ). The frequency of recording EJCs in this second group was more accurately determined by extending the number of stimuli applied to 200. Addition of clonidine $(0.5 \mu \mathrm{M})$ to CST preparations completely abolished evoked transmitter release (Figure 3 compare A with B). Neither the shape nor regularity of the NTI were affected by the addition of clonidine $(0.5 \mu \mathrm{M})$.

\section{Effect of chronic clonidine treatment on transmitter release}

The success rate of recording EJCs from sympathetic varicosities of chronically clonidine treated (CCT) animals was examined next. Clonidine $(0.5 \mu \mathrm{M})$ abolished evoked transmitter release in CST preparations bathed in $2 \mathrm{mM}$ $\left[\mathrm{Ca}^{2+}\right]_{\mathrm{o}}$ during $0.1 \mathrm{~Hz}$ stimulation (Figure $3 \mathrm{~B} ; 100 \%$ failures). However, under the same conditions, CCT preparations bathed in clonidine $(0.5 \mu \mathrm{M})$ were tolerant to clonidine, such that the average probability of release in CCT preparations bathed in clonidine $(0.5 \mu \mathrm{M})$ was not significantly different from the average probability of release seen in CST preparations without clonidine (Figure 3C). In CST preparations bathed in $2 \mathrm{mM}\left[\mathrm{Ca}^{2+}\right]_{\mathrm{o}}$ with idazoxan $(1 \mu \mathrm{M}), 92 \%$ of varicosities had a probability of transmitter release less than 0.05 . The remaining $8 \%$ of varicosities had transmitter release probabilities ranging from 0.05 to 0.44 (Figure 4A). The success rate of recording EJCs from CCT preparations 


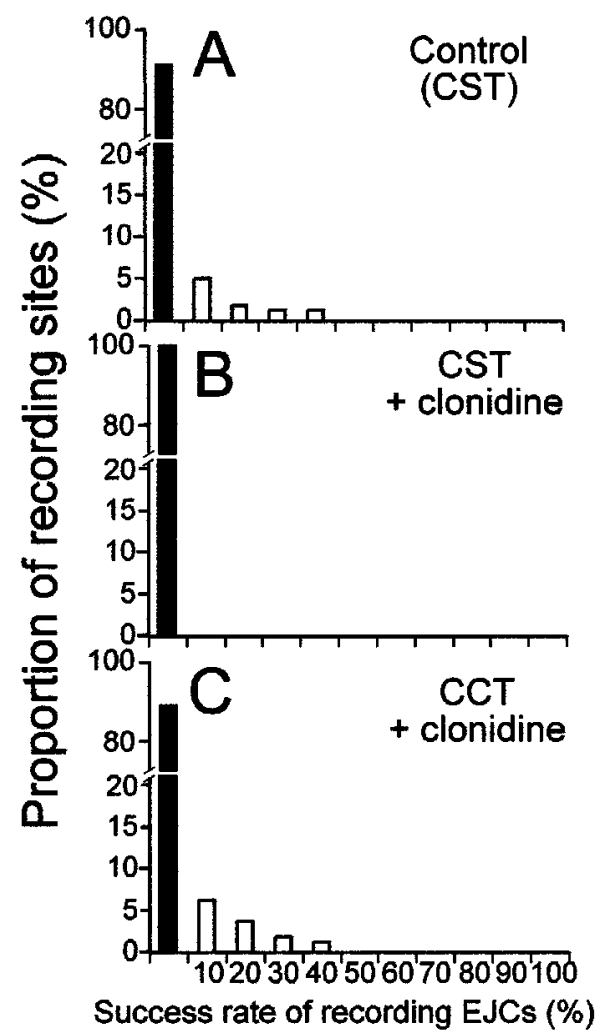

Figure 3 Effect of acute clonidine administration on the success of recording EJCs from sets of sympathetic varicosities. (A) CST preparations ( $n=12$ preparations, 149 sets of varicosities) before administration of clonidine; (B) CST preparations following $20 \mathrm{~min}$ bathing in clonidine $(0.5 \mu \mathrm{M} ; n=12$ preparations, 120 sets of varicosities); (C) CCT preparations bathed in clonidine $(0.5 \mu \mathrm{M}$; $n=11$ preparations, 114 sets of varicosities). The percentage of release sites with a probability of release less than 0.05 are indicated by the black bar. Note that transmitter release is abolished by clonidine in CST preparations but not in CCT preparations.

bathed in idazoxan $(1 \mu \mathrm{M})$ was greater than for CST preparations (Figure 4 compare $\mathrm{A}$ and $\mathrm{C}$ ). In CCT preparations bathed in idazoxan $(1 \mu \mathrm{M})$, only $59 \%$ of varicosities had transmitter release probabilities less than 0.05 (compared with $92 \%$ in CST preparations). Transmitter release probabilities for the remaining $41 \%$ of varicosities varied between 0.05 and 1 (Figure 4C). These results suggest a tolerance to clonidine in CCT preparations. This tolerance is exposed during acute, idazoxan induced withdrawal and manifests itself as a significant $(P<0.05)$ increase in transmitter release probabilities.

\section{Effect of changing $\left[\mathrm{Ca}^{2+}\right]_{o}$ and stimulation frequency on transmitter release in CST and CCT preparations}

Previous studies have shown that the inhibitory effects of clonidine can be reduced by increasing the intracellular calcium concentration (Alberts et al., 1981; Illes \& Dorge, 1985; Starke, 1987). We therefore examined the effect of increasing the $\left[\mathrm{Ca}^{2+}\right]_{0}$ and stimulation frequency on the inhibitory effects of clonidine in CST preparations and CCT preparations. In these experiments, CST preparations in $1 \mu \mathrm{M}$ idazoxan were treated as the control (due to the absence of $\alpha_{2}$-adrenoceptor mediated inhibition). Due to the counter-

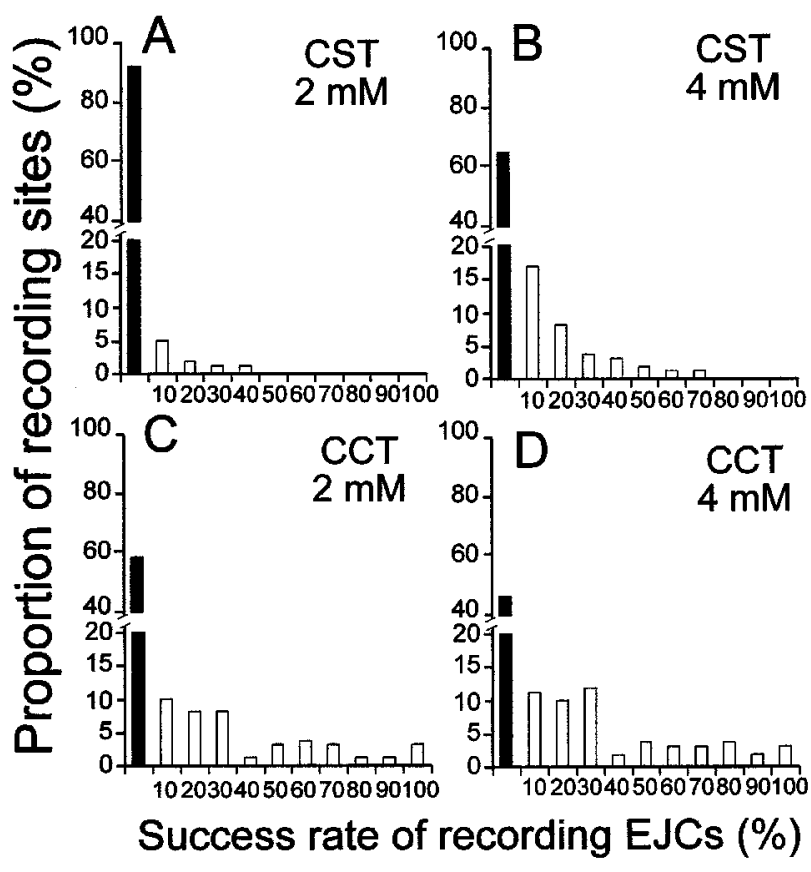

Figure 4 Effect of chronic clonidine treatment on the success of recording EJCs from sets of sympathetic varicosities. (A) The probability of transmitter release in CST preparations bathed in $2 \mathrm{~mm}$ calcium ( $n=149$ sets of varicosities from 12 preparations) (B) CST preparations bathed in $4 \mathrm{~mm}$ calcium $(n=104$ sets of varicosities from 12 preparations) (C) The probability of transmitter release in CCT preparations bathed in $2 \mathrm{mM}$ calcium $(n=114$ sets of varicosities from 11 preparations) (D) CCT preparations bathed in $4 \mathrm{~mm}$ calcium ( $n=67$ sets of varicosities from 11 preparations). All preparations were bathed in idazoxan $(1 \mu \mathrm{M})$ for greater than $20 \mathrm{~min}$ before recordings were taken. The percentage of recording sites with a probability of release less than 0.05 are indicated by the black bars.

adaptive increase in transmitter release probabilities seen in CCT preparations, CCT preparations in the presence of $0.5 \mu \mathrm{M}$ clonidine were treated as the control for CCT animals.

In CST preparations, raising the $\left[\mathrm{Ca}^{2+}\right]_{0}$ from $2-4 \mathrm{mM}$ decreased the percentage of varicosities with a probability of transmitter release less then 0.05 from 92 to $64 \%$ (Figure 4A, B). The remaining $36 \%$ of varicosities at $4 \mathrm{~mm}$ had release probabilities as high as 0.68 (compared with 0.44 in $2 \mathrm{mM}$ calcium). When the $\left[\mathrm{Ca}^{2+}\right]_{\mathrm{o}}$ was increased from 2 to $4 \mathrm{~mm}$ for CCT preparations, the percentage of varicosities with a probability of release less than 0.05 decreased from $59-47 \%$ (Figure 4C,D). Complex signals (combined positive and negative currents) were observed at some of the recording sites. These reflect simultaneous transmitter releases occurring both inside and outside the rim of the recording electrode. The nature of these signals makes it impossible to accurately measure the amplitude of either negative or positive going EJCs. As such, preparations that developed complex signals were halted and the occurrence of the signal was noted. The frequency of such recordings was higher in the CCT preparations bathed in idazoxan $(1 \mu \mathrm{M})$ and especially in preparations that were bathed in $4 \mathrm{mM}\left[\mathrm{Ca}^{2+}\right]_{0}$ reflecting higher probabilities of release. The relative frequency of complex EJCs for CST and CCT preparations bathed in idazoxan $(1 \mu \mathrm{M})$ was 2 and $34 \%$ respectively when the $\left[\mathrm{Ca}^{2+}\right]_{0}$ was $2 \mathrm{~mm}$ (data not shown). 
We next examined the effect of different $\left[\mathrm{Ca}^{2+}\right]_{0}$ and stimulation frequencies on the inhibitory effects of clonidine. In both CST and CCT preparations, increasing $\left[\mathrm{Ca}^{2+}\right]_{\mathrm{o}}$ from 1 to $4 \mathrm{mM}$ increased EJC amplitude (Figure 5A). In general, the magnitude of the increase in EJC amplitude was inversely proportional to the initial probability of transmitter release from the sympathetic varicosities. That is, larger increases in EJC amplitude were seen when the initial probability of release was lower (see Table 1 and Figure 5A,B). Clonidine $(0.5 \mu \mathrm{M})$ completely abolished transmitter release in CST preparations bathed in $2 \mathrm{mM}\left[\mathrm{Ca}^{2+}\right]_{0}$. Increasing the $\left[\mathrm{Ca}^{2+}\right]_{\mathrm{o}}$ from 2 to $4 \mathrm{~mm}$ had no effect on the inhibitory action of clonidine in CST preparations (open triangles, Figure 5A). Increasing the frequency of stimulation from 0.1 to $1.0 \mathrm{~Hz}$ in these preparations resulted in a reduction of the inhibitory effects of clonidine at $2 \mathrm{mM}$ calcium (open triangles, Figure 5B). Simultaneously, increasing the stimulation frequency from 0.1 to $1 \mathrm{~Hz}$ and raising the $\left[\mathrm{Ca}^{2+}\right]_{\mathrm{o}}$ from 2 to $4 \mathrm{mM}$ effectively reversed the inhibitory effects of clonidine $(0.5 \mu \mathrm{M})$ on EJC amplitude in CST preparations (Figure 5, compare open triangles in A with open triangles in B). CCT preparations however, were tolerant to clonidine $(0.5 \mu \mathrm{M})$ at
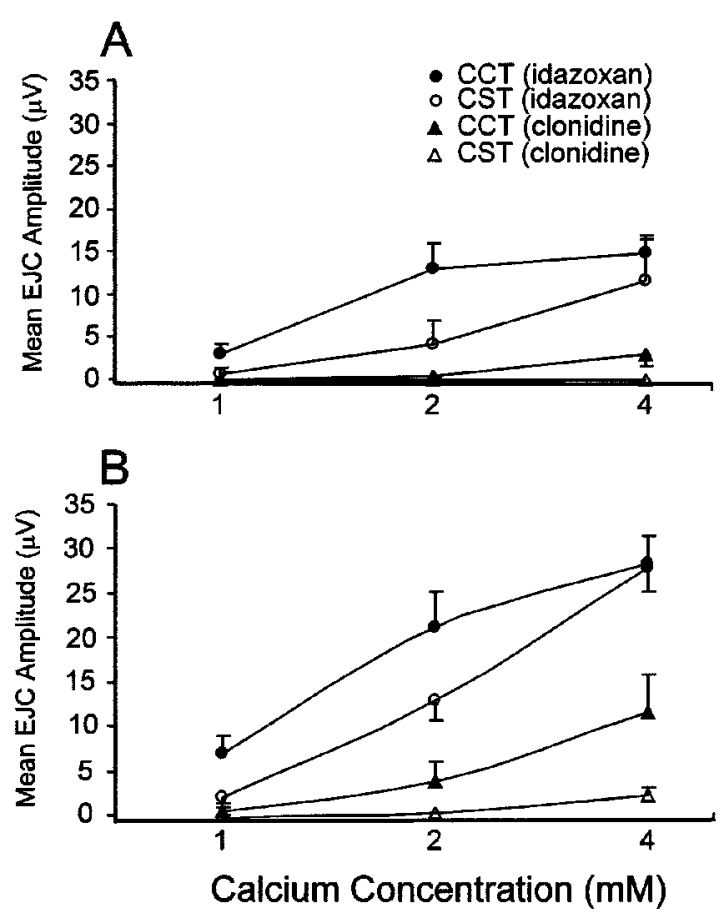

Figure 5 Effect of changing the frequency of nerve stimulation and $\left[\mathrm{Ca}^{2+}\right]_{\mathrm{o}}$ on the average EJC amplitude for CST (open symbols) and CCT (filled symbols) preparations. Two different frequencies of stimulation were examined: (A) $0.1 \mathrm{~Hz}$ and (B) $1 \mathrm{~Hz}$. The $\left[\mathrm{Ca}^{2+}\right]_{\mathrm{o}}$ was increased from 1 to $4 \mathrm{~mm}$. Symbols indicate the mean and s.e.mean. Addition of clonidine $(0.5 \mu \mathrm{M})$ to CST preparations $(n=12)$ abolished transmitter release when stimulated at $0.1 \mathrm{~Hz}$ in 1 to $4 \mathrm{~mm}$ $\left[\mathrm{Ca}^{2+}\right]_{\mathrm{o}}$. The inhibitory effect of clonidine $(0.5 \mu \mathrm{M})$ on CST preparations could be reduced by stimulating at $1 \mathrm{~Hz}$ in 2 or $4 \mathrm{~mm}$ calcium (open triangles). The mean EJC amplitude in CCT preparations $(n=11)$ bathed in clonidine $(0.5 \mu \mathrm{M}$; filled triangles $)$ was significantly $(P<0.05)$ higher than in CST preparations bathed in clonidine $(0.5 \mu \mathrm{M}$; open triangles). The mean EJC amplitudes in CCT preparations bathed in idazoxan $(1 \mu \mathrm{M}$; filled circles $)$ were greater than mean EJC amplitudes in CST preparations in idazoxan ( $1 \mu \mathrm{M}$; open circles).
Table 1 The magnitude of the increase on transmitter release

\begin{tabular}{ccccc}
\hline \multicolumn{2}{c}{$C S T$} & \multicolumn{2}{c}{$C C T$} \\
& $0.1 \mathrm{~Hz}$ & $1 \mathrm{~Hz}$ & $0.1 \mathrm{~Hz}$ & $1 \mathrm{~Hz}$ \\
$1-2{\mathrm{~mm}\left[\mathrm{Ca}^{2+}\right]_{\mathrm{o}}}^{4} 4.28 \pm 0.52$ & $6.06 \pm 1.07$ & $4.01 \pm 0.59$ & $3.14 \pm 0.56$ \\
$2-4 \mathrm{~mm}\left[\mathrm{Ca}^{2+}\right]_{\mathrm{o}}$ & $3.67 \pm 0.43$ & $1.58 \pm 0.39$ & $1.36 \pm 0.29$ & $1.36 \pm 0.32$
\end{tabular}

$2 \mathrm{~mm}\left[\mathrm{Ca}^{2+}\right]_{\mathrm{o}}$ and $0.1 \mathrm{~Hz}$ stimulation such that the mean EJC amplitude of CCT preparations in clonidine $(0.5 \mu \mathrm{M})$ was not significantly different $(P>0.05)$ to the mean EJC amplitude of CST preparations without clonidine (Figure 5A, filled triangles). Increasing the $\left[\mathrm{Ca}^{2+}\right]_{\mathrm{o}}$ from 2 to $4 \mathrm{mM}$ and/or increasing the frequency of stimulation from 0.1 to $1.0 \mathrm{~Hz}$ further reduced the inhibitory effect of clonidine $(0.5 \mu \mathrm{M}$; Figure 5B, filled triangles). At all $\left[\mathrm{Ca}^{2+}\right]_{\mathrm{o}}$ and stimulation frequencies studied, acutely withdrawn CCT preparations (idazoxan $1 \mu \mathrm{M})$ had significantly higher $(P<0.05)$ EJC amplitudes than preparations in the presence of clonidine $(0.05 \mu \mathrm{M}$; compare filled circles and filled triangles in Figure $5)$.

\section{Discussion}

\section{The effect of clonidine on the NTI and transmitter release}

We have investigated the effects of clonidine on the NTI and transmitter release from sympathetic varicosities of single axons in guinea-pig vasa deferentia. Single axons with varicosities regularly spaced at $3-5 \mu \mathrm{m}$ intervals were visualized using $\mathrm{DiOC}_{2}(5)$-fluorescence to aid in the placement of small diameter electrodes over groups of 4-6 varicosities. Neither the amplitude nor regularity of the NTI varied when the stimulation voltage was changed, suggesting that the recordings all came from single axons. Furthermore, neither the amplitude nor the duration of the NTI were affected by a concentration of clonidine $(0.5 \mu \mathrm{M})$ that abolished EJCs. This result supports several recent suggestions that $\alpha_{2}$-adrenoceptor inhibition in the vas deferens is due to inhibition of voltage gated calcium channels (VGCCs) rather than reduced $\mathrm{K}^{+}$conductance (Brock \& Cunnane, 1995; MacMillan et al., 1996; Altman et al., 1999).

It is possible that clonidine may interfere directly with $\mathrm{Ca}^{2+}$ entry or a step downstream from $\mathrm{Ca}^{2+}$ entry, thus affecting the calcium sensitivity of the terminal. Several lines of evidence suggest that clonidine acts to directly inhibit the VGCCs, thus decreasing calcium influx into the terminal. First, the inhibitory effects of clonidine on transmitter release are reduced by increasing $\left[\mathrm{Ca}^{2+}\right]_{\mathrm{o}}$, increasing the stimulation frequency or prolonging the duration of the NTI with $\mathrm{K}^{+}$ channel blockers (Alberts et al., 1981; Ebstein et al., 1982; Schoffelmeer \& Mulder, 1983; Wakade \& Wakade, 1983; Starke, 1987). This reversibility of pre-synaptic inhibition is characteristic of G-protein mediated inhibition of VGCCs (for review, see Dolphin, 1995; 1998). Second, both MacMillan et al. (1996) and Altman et al. (1999) have shown that a point mutation on the $\alpha_{2 \mathrm{~A}}$-adrenoceptor that prevents activation of $\mathrm{K}^{+}$currents without affecting the $\mathrm{Ca}^{2+}$ currents, does not affect the ability of the receptor to inhibit 
transmitter release. Finally, studies by Horn \& McAfee (1980) and later by Boehm \& Huck (1991) have shown directly, that calcium influx in sympathetic neurons is inhibited by clonidine. Brain \& Bennett (1997) demonstrated a $46 \%$ reduction in single impulse evoked calcium entry in the sympathetic terminals of the vas deferens following exposure to clonidine $(1 \mu \mathrm{M})$.

However, in contradiction to these results, one recent publication suggests that clonidine only reduces calcium influx in two out of nine varicosities in the mouse vas deferens (O'Connor et al., 1999). This observation may be explained by the 'lateral inhibition' hypothesis put forward by Brock et al. (1990); Brock \& Cunnane (1991). However, O'Connor et al. (1999) also suggested that increasing the stimulation frequency increases the inhibitory effect of clonidine on $\mathrm{Ca}^{2+}$ influx rather than decreasing it. Our present results, which have examined transmitter release from single sympathetic axons, support the hypothesis that inhibition of transmitter release by clonidine is reversed by increasing the stimulation frequency or the $\left[\mathrm{Ca}^{2+}\right]_{\mathrm{o}}$.

It is possible that clonidine may exert its inhibitory effect on transmitter release downstream from calcium entry. Several recent papers have suggested that the calcium sensitivity of the nerve terminals may play a role in determining the probability of transmitter release (Redman et al., 1997; Msghina et al., 1999). Clonidine may alter the sensitivity of transmitter release to calcium by acting on the release machinery. Morphine treatment has been shown to affect the phosphorylation of synapsin-1 (Nah et al., 1993). Clonidine, which acts through similar, if not identical Gproteins, may have a similar effect on the phosphorylation of release machinery proteins thus inhibiting transmitter release downstream of calcium entry.

\section{Effect of CCT on evoked transmitter release from sympathetic varicosities of the guinea-pig vas deferens}

CCT preparations were tolerant to clonidine compared with CST preparations. During idazoxan induced acute with-

\section{References}

ALBERTS, P., BARTFAI, T. \& STJARNE, L. (1981). Site(s) and ionic basis of alpha-autoinhibition and facilitation of "3H'noradrenaline secretion in guinea-pig vas deferens. J. Physiol. (Lond.), 312, $297-334$

ALBLAS, J., VAN CORVEN, E.J., IIORDIJK, P.L., MILliGAN, G. \& MOOLENAAR II, W. (1993). Gi-mediated Activation of the p21ras-mitogen-activated Protein Kinase Pathway by $\alpha_{2}$-adrenergic Receptors Expressed in Fibroblasts. J. Biol. Chem., 268, $22235-22238$.

ALTMAN, J.D., TRENDELENBURG, A.U., MACMILLAN, L., BERNSTEIN, D., LIMBIRD, L., STARKE, K., KOBILKA, B.K. \& HEIN, L. (1999). Abnormal regulation of the sympathetic nervous system in alpha2A- adrenergic receptor knockout mice. Mol. Pharmacol., 56, $154-161$.

ANDRADE, R. \& AGHAJANIAN, G.K. (1985). Opiate- and alpha 2adrenoceptor-induced hyperpolarizations of locus ceruleus neurons in brain slices: reversal by cyclic adenosine $3^{\prime}: 5^{\prime}$ monophosphate analogues. J. Neurosci., 5, 2359-2364.

BOEHM, S. \& HUCK, S. (1991). Modulation of calcium currents via alpha 2-adrenoceptors in embryonic chick sympathetic neurons. Naunyn Schmiedebergs Arch. Pharmacol., 344, 382-385. drawal from clonidine, CCT preparations showed a significant $(P<0.05)$ increase in the probability of transmitter release. Similar increases in the probability of transmitter release from sympathetic varicosities of the mouse vas deferens have been reported during acute withdrawal from chronic morphine treatment (Einstein \& Lavidis, 1984a, b; Lavidis, 1995a, b). This enhancement of transmitter release during acute withdrawal from chronic morphine treatment is the result of an increase in the probability of release (Lavidis, 1995a; Karunanithi \& Lavidis, 2001) and an increase in the density of innervation (Karunanithi \& Lavidis, 2001). Prolonged exposure to morphine can alter genetic expression at the nucleus through the mitogen activated protein kinase (MAPK) pathway (for review, see Williams et al., 2001). Activation of the $\alpha_{2}$-adrenoceptors has also been shown to activate the MAPK pathway (Alblas et al., 1993). Given that both opiates and $\alpha_{2}$-adrenoceptor agonists act on the $G_{i}$ and $G_{o}$ G-proteins, it is possible that prolonged exposure to $\alpha_{2}$ adrenoceptors will produce similar cellular adaptations as seen following prolonged exposure to opiates.

\section{Conclusion}

The present study has demonstrated an increase in the probability of transmitter release from sympathetic varicosities following chronic presynaptic inhibition of transmitter release with clonidine. The observations of the present study and previous studies involving chronic morphine treatment (Montel et al., 1975; Einstein \& Lavidis, 1984b; Solomon \& Gebhart, 1988; Stevens et al., 1988; Lavidis, 1995b; Williams et al., 2001) suggest that prolonged pre-synaptic inhibition activates counter-adaptive changes in the mechanism of transmitter release which is manifested as an increase in the probability of transmitter release during acute withdrawal.

This work was funded by a NH \& MRC grant.
BRAIN, K.L. \& BENNETT, M.R. (1997). Calcium in Sympathetic Varicosities of Mouse Vas Deferens During Facilitation, Augmentation and Autoinhibition. J. Physiol., 502, 521-536.

BROCK, J.A. \& CUNNANE, T.C. (1987). Relationship between the nerve action potential and transmitter release from sympathetic postganglionic nerve terminals. Nature, 326, 605-607.

BROCK, J.A. \& CUNNANE, T.C. (1988). Electrical activity at the sympathetic neuroeffector junction in the guinea-pig vas deferens. J. Physiol. (Lond)., 399, 607-632.

BROCK, J.A. \& CUNNANE, T.C. (1991). Local application of drugs to sympathetic nerve terminals: an electrophysiological analysis of the role of prejunctional alpha- adrenoceptors in the guinea-pig vas deferens. Br. J. Pharmacol., 102, 595-600.

BROCK, J.A. \& CUNNANE, T.C. (1995). Effects of $\mathrm{Ca} 2+$ and $\mathrm{K}+$ channel blockers on nerve impulses recorded from guineapig postganglionic sympathetic nerve terminals. J. Physiol. (Lond)., 489, $389-402$. 
BROCK, J.A., CUNNANE, T.C., STARKE, K. \& WARDELL, C.F. (1990). Alpha 2-adrenoceptor-mediated autoinhibition of sympathetic transmitter release in guinea-pig vas deferens studied by intracellular and focal extracellular recording of junction potentials and currents. Naunyn Schmiedebergs Arch. Pharmacol., 342, 45-52.

BROWN, D.A. \& CAULFIELD, M.P. (1979). Hyperpolarizing 'alpha 2'adrenoceptors in rat sympathetic ganglia. Br.J. Pharmacol., 65, $435-445$.

COLE, A.E. \& SHINNICK-GALLAGHER, P. (1981). Comparison of the receptors mediating the catecholamine hyperpolarization and slow inhibitory postsynaptic potential in sympathetic ganglia. $J$. Pharmacol. Exp. Ther., 217, 440-444.

DOLPHIN, A.C. (1995). The G.L. Brown Prize Lecture. Voltagedependent calcium channels and their modulation by neurotransmitters and G proteins. Exp. Physiol., 80, 1-36.

DOLPHIN, A.C. (1998). Mechanisms of modulation of voltagedependent calcium channels by $\mathrm{G}$ proteins. J. Physiol., 506, $3-$ 11.

DUNLAP, K. \& FISCHBACH, G.D. (1981). Neurotransmitters decrease the calcium conductance activated by depolarization of embryonic chick sensory neurones. J. Physiol., 317, 519-535.

EBSTEIN, R.P., SEAMON, K., CREVELING, C.R. \& DALY, J.W. (1982). Release of norepinephrine from brain vesicular preparations: effects of an adenylate cyclase activator, forskolin, and a phosphodiesterase inhibitor. Cell. Mol. Neurobiol., 2, 179-192.

EINSTEIN, R. \& LAVIDIS, N.A. (1984a). The dependence of excitatory junction potential amplitude on the external calcium concentration in mouse vas deferens during narcotic withdrawal. $\mathrm{Br} . J$. Pharmacol., 83, 863-870.

EINSTEIN, R. \& LAVIDIS, N.A. (1984b). The dependence of excitatory junction potential amplitude on the external calcium concentration in narcotic tolerant mouse vas deferens. Br. J. Pharmacol., 83, $853-861$.

HORN, J.P. \& MCAFEE, D.A. (1980). Alpha-drenergic inhibition of calcium-dependent potentials in rat sympathetic neurones. $J$. Physiol. (Lond.), 301, 191-204.

ILLES, P. \& DORGE, L. (1985). Mechanism of alpha 2-adrenergic inhibition of neuroeffector transmission in the mouse vas deferens. Naunyn Schmiedebergs Arch. Pharmacol., 328, $241-$ 247.

KARUNANITHI, S. \& LAVIDIS, N.A. (2001). Effect of chronic morphine treatement on $\alpha_{2}$-adrenoceptor mediated autoinhibition of transmitter release from sympathetic varicosities of the mouse vas deferens. Br. J. Pharmacol., 132, 403-410.

LAVIDIS, N.A. (1995a). Effect of chronic morphine treatment on transmitter release from sympathetic varicosities of the mouse vas deferens. Br. J. Pharmacol., 116, 2860-2865.

LAVIDIS, N.A. (1995b). Effect of morphine on the nerve terminal impulse and tranmitter release from sympathetic varicosities innervating the mouse vas deferens. Br. J. Pharmacol., 116, $2852-2859$

LAVIDIS, N.A. \& BENNETT, M.R. (1992). Probabilistic secretion of quanta from visualised sympathetic nerve varicosities in mouse vas deferens. J. Physiol., 454, 9-26.

LAVIDIS, N.A. \& BENNETT, M.R. (1993a). Probabilistic secretion of quanta from successive sets of visualized varicosities along Single sympathetic nerve terminals. J. Auto. Nervous. Sys., 43, 41-50.

LAVIDIS, N.A. \& BENNETT, M.R. (1993b). Sympathetic innervation of the surface of the mouse vas deferens. J. Auto. Nerv. Syst., 45, $87-100$.
MACMILLAN, L.B., HEIN, L., SMITH, M.S., PIASCIK, M.T. \& LIMBIRD, L.E. (1996). Central hypotensive effects of the alpha2aadrenergic receptor subtype. Science, 273, 801-803.

MONTEL, H., STARKE, K. \& TAUBE, H.D. (1975). Morphine tolerance and dependence in noradrenaline neurones of the rat cerebral cortex. Naunyn Schmiedebergs Arch. Pharmacol., 288, 415-426.

MSGHINA, M., MILlAR, A.G., CHARLTON, M.P., GOVIND, C.K. \& ATWOOD, H.L. (1999). Calcium entry related to active zones and differences in transmitter release at phasic and tonic synapses. $J$. Neurosci., 19, 8419-8434.

NAH, S.Y., SAYA, D., BARG, J. \& VOGEL, Z. (1993). Opiate receptor agonists regulate phosphorylation of synapsin I in cocultures of rat spinal cord and dorsal root ganglion. Proc. Natl. Acad. Sci. USA, 90, 4052-4056.

NORTH, R.A. \& SURPRENANT, A. (1985). Inhibitory synaptic potentials resulting from alpha 2-adrenoceptor activation in guinea-pig submucous plexus neurones. J. Physiol. (Lond)., 358, $17-33$.

O'CONNOR, S.C., BRAIN, K.L. \& BENNETT, M.R. (1999). Individual sympathetic varicosities possess different sensitivities to alpha 2 and $\mathrm{P} 2$ receptor agonists and antagonists in mouse vas deferens. Br. J. Pharmacol., 128, 1739-1753.

REDMAN, R.S., SEARL, T.J., HIRSH, J.K. \& SILINSKY, E.M. (1997) Opposing effects of phorbol esters on transmitter release and calcium currents at frog motor nerve endings. J. Physiol. (Lond)., 501, $41-48$.

SCHOFFELMEER, A.N. \& MULDER, A.H. (1983). Differential control of $\mathrm{Ca}^{+}{ }^{+}$-dependent $[3 \mathrm{H}]$ noradrenaline release from rat brain slices through presynaptic opiate receptors and alpha- adrenoceptors. Eur. J. Pharmacol., 87, 449-458.

SOLOMON, R.E. \& GEBHART, G.F. (1988). Intrathecal morphine and clonidine: antinociceptive tolerance and cross- tolerance and effects on blood pressure. J. Pharmacol. Exp. Ther., 245, $444-$ 454.

STARKE, K. (1987). Presynaptic alpha-autoreceptors. Rev. Physiol. Biochem. Pharmacol., 107, 73-146.

STEVENS, C.W., MONASKY, M.S. \& YAKSH, T.L. (1988). Spinal infusion of opiate and alpha-2 agonists in rats: tolerance and cross-tolerance studies. J. Pharmacol. Exp. Ther., 244, 63-70.

SURPRENANT, A., HORSTMAN, D.A., AKBARALI, H. \& LIMBIRD, L.E. (1992). A point mutation of the alpha 2-adrenoceptor that blocks coupling to potassium but not calcium currents. Science, 257, 977-980.

WAKADE, A.R. \& WAKADE, T.D. (1983). Mechanism of negative feed-back inhibition of norepinephrine release by alpha-adrenergic agonists. Neuroscience, 9, 673-677.

WILLIAMS, J.T., CHRISTIE, M.J. \& MANZONI, O. (2001). Cellular and Synaptic Adaptations Mediating Opioid Dependence. Physiol. Rev., 81, 299-343.

WILLIAMS, J.T., HENDERSON, G. \& NORTH, R.A. (1985). Characterization of alpha 2-adrenoceptors which increase potassium conductance in rat locus coeruleus neurones. Neuroscience, $\mathbf{1 4}$ $95-101$.

WILLIAMS, J.T. \& NORTH, R.A. (1985). Catecholamine inhibition of calcium action potentials in rat locus coeruleus neurones. Neuroscience, 14, $103-109$.

YOSHIKAMI, D. \& OKUN, L.M. (1984). Staining of living presynaptic nerve terminals with selective fluorescent dyes. Nature, 310, $53-$ 56.

(Received July 24, 2001

Revised August 28, 2001 Accepted September 10, 2001) 